\title{
The Pattern of Cooperation between the Ministry of Environment and Forestry of the Republic of Indonesia and the Wildlife Conservation Society-Indonesia Programme in Dealing with the Illegal Transnational Trade of Pangolins in Indonesia
}

\author{
Afifah Rahmi Andini, ${ }^{1}$, and Hartuti Purnaweni ${ }^{2}$ \\ ${ }^{1}$ Master Program of Environmental Science, School of Postgraduate Studies, Diponegoro University, Semarang - Indonesia \\ ${ }^{2}$ Doctoral Program of Environmental Science, School of Postgraduate Studies, Diponegoro University, Semarang - Indonesia
}

\begin{abstract}
Indonesia is home to one of the world's pangolins species whose status is protected internationally in the Appendix 1 Category of CITES (Convention on International Trade in Endangered Species of Wild Fauna and Flora). This means that pangolins are categorized vulnerable to extinction and are prohibited to be freely traded. However, since 1990, the number of pangolin populations in Indonesia has declined because of the threat of environmental degradation, illegal hunting and illegal trade. In responding the threat of pangolin extinction in Indonesia, the Indonesian government formed a collaborative initiative with International Non-Government Organizations working on wildlife conservation. This study aims to analyze the pattern of cooperation between the Ministry of Environment and Forestry (KLHK) with the Wildlife Conservation Society-Indonesia Programme (WCS-IP) in dealing with the illegal transnational trade of pangolins. This study used an analysis of interaction patterns of supplementary, complementary, and adversary in a state-non-state actor cooperation approach. The findings in this study showed that cooperation established based on supplementary patterns is carried out by providing capacity building assistance of law enforcement officers from WCS-IP to KLHK. The complementary pattern was by giving mandate to carry out the program from KLHK to WCS-IP, and the adversary pattern was by providing support as well as input by WCS-IP on government regulations and policies. Based on the analysis of the all of the patterns, the cooperation established is more dominated by using supplementary and complementary patterns because of the compatibility of the vision and mission, the intensity of coordination and trust of both parties.
\end{abstract}

Keywords: KLHK; WCS-IP; pangolins; illegal transnational trade; supplementary; complementary; adversaries.

\section{Introduction}

Indonesia is one of the countries with the biggest biodiversity in the world. Unfortunately, without ignoring management efforts to conserve these natural wealth, Indonesia has long been known as a significant center for illegal wildlife trade [1]. Traders exploit Indonesia as a source of illegal wildlife products from main species such as the Tiger Panthera Tigris, various species of primates and honey bears. The black market of endangered flora and fauna species, from and to Indonesia, is widespread and involves trade chains both nationally and internationally. A recent report that analysis wildlife crime in Indonesia shows that the growing pattern of illegal trade involving organized criminal networks is increasing [2]. Among a huge number of species of wildlife raded on international and domestic markets in Indonesian pangolins are one of them.
Based on data reported by TRAFFIC, Pangolin is one of the most smuggled species in the black market of global wildlife trade. In the report, there were 111 records of pangolin confiscation in a 6-year period in which Indonesia was involved as a supplier, confiscation, or in one case, as a destination country. The confiscation records, which recorded live or dead pangolin confiscations, scales and other body parts, were of 35,632 pangolins, or an average of 321 per confiscation (with a median of 34 per confiscation). Of these numbers, it is estimated that only about 2,884 were found alive, in other word most of the confiscations $(79 \%)$ were confiscations of nonliving specimens or body parts [3].

Based on the findings of the illegal pangolin trade case that occurred in Indonesia, with all kinds of motives and their consequences, it is an obligation for the Indonesian government to respond quickly to follow up the problem. In general, the response of the Indonesian government is divided into two, which is through the

* Corresponding author: afifahrahmiandinis@gmail.com 
legislative channels and improvement in the quality and quantity of the authorities. Through the legislative channel, Indonesia has ratified an international convention related to the preservation of endangered flora and fauna, which is the Convention on International Trade on Endangered Species of Wild Flora and Fauna (CITES) through Presidential Decree Number 43 of 1978 and made a derivative regulation which is Law number 05 of 1990 concerning Conservation Natural Resources and Ecosystems [4].

Whereas in improving the quality and quantity of authorities in handling illegal hunting and cross-border trade of pangolin bodies, the Indonesian Government through the Ministry of Environment and Forestry has made improvements to the practical aspects. One of the efforts carried out by the relevant Ministries is to do a cooperation with International Non-Government Organizations (INGO), some of them are the World Wildlife Fund, the Wildlife Conservation Society and the International Union for the Conservation of Nature.

This study will focus on INGO-WCS-IP. The selection of WCS-IP has gone through several considerations that underlie why this research needs to be done. First, because WCS-IP is one of the oldest and largest organizations that has extensive networks throughout the world and is the longest-running organization in Indonesia. Second, WCS-IP is trusted as a partner of the Indonesian Government in several strategic pangolin conservation locations in Indonesia. And third, in addition to cooperating with the Indonesian Government in monitoring pangolins in conservation areas, WCS-IP also conducts several comprehensive programs. One of which is going directly in the field to take action and education in order to make prevention.

Based on those three reasons, there is one interesting thing that needs to be studied and further elaborated as an illustration of the cooperation between the two parties. That is how each party, either KLHK or WCS-IP IP, did a cooperation pattern. The pattern of cooperation is interesting and important to be investigated as an effort to dissect and enrich the study of the pattern of cooperation between state and non-state actors.

Based on the description above, the author is interested in conducting research and presenting in a scientific work in the form of a paper with the title: "Analysis of the Pattern of Cooperation between KLHK with WCS-IP in Dealing with the Transnational Illegal Trade of Pangolins". This study aims to analyze the pattern of cooperation between KLHK and WCS-IP as INGO in dealing with illegal pangolin trade in Indonesia. This research used the concept of cooperation between the government and INGO. This concept can be used to analyze how WCS-IP behavior patterns in Indonesia and their performance through a framework of cooperation between KLHK and WCS-IP in handling illegal trade of pangolins.

\section{Method}

This research used an analysis of interaction patterns of supplementary, complementary, and adversary in a state- non-state actor cooperation approach. In conducting the research by qualitative method, the authors used primary and secondary data. Primary data is reached by interview with stakeholders which majoring that issue, that is Ministry of Environment and Forestry of Republic Indonesia and Wildlife Conservation Society - Indonesia Programme. And secondary data is, a data reached by reviewing some literatures, such as books, journal, and scientific text. The data obtained is processed, studied and analyzed by using descriptive method, in which the overall data is described and analyzed thoroughly and systematically so as to obtain clear and accurate.

\section{Discussions}

\subsection{The Problem of Illegal Trade of Pangolins in Indonesia and the Responses of State and Non- State Actors}

Indonesia, is a home to one of the world's pangolin species, Manis javanica or Javanese Pangolin [5] which is one of the species found in Indonesia. This animal is unique because its entire body is covered with scales, has a tongue that is half the length of the body (the length of the body is $50-60 \mathrm{~cm}$ ), and have no teeth [5].

Javanese pangolins is categorized nocturnal animals that can be found in both primary and secondary forests, and cultivation areas including plantation areas, ecotone areas or transition zones between forests and community gardens that have shrubs where this habitat provides their food in the form of ants and termites [6]. Therefore, this animal can be said to be a pest controller because adult pangolins are estimated to be able to eat more than 70 thousand insects per year [7].

The population of Javanese pangolin is declining because it is caused by a number of activities which are detrimental to them. These activities are in the form of deforestation and forest degradation, hunting followed by illegal trade of the pangolin body parts and poverty [3]. Based on these activities, hunting and illegal trade of pangolin body parts are activities classified as transnational crime.

Illegal hunting and illegal trading of pangolins are inseparable forms of crime. The illegal hunting of pangolins began to spread since 1925, which was triggered by high black market demand for parts of the body of the pangolin. The high demand is due to the belief in the efficacy of the body parts of the pangolin and as a manifestation of the luxury of its consumers [8].

In general, the practice of illegal hunting and illegal trade of pangolins in Indonesia involves six main actors that can be grouped into three parts, which are the executor group, facilitator group, and crime users. The executor group is a group of perpetrators who catch pangolins from their habitat, which is the local community. The facilitator group is a group of actors who mediate the illegal trading of pangolins, including capital owners or collectors, ship captains and government officials or law enforcement officers whose role is to assist the pangolin trade. Crime user groups are the last group of perpetrators in the illegal pangolin 
trading chain, which are local and foreign entrepreneurs [9].

As for the share of illegal trade of pangolin body parts, East Asia is still the target of a lucrative global market for the actors. China is one of the countries that import illegal pangolin body parts which is quite high. Based on the TRAFFIC report, in the span of time between 2010 and 2016, there were 12 findings of cases of pangolin trade from Indonesia to China. The total number of pangolins seized in this case is estimated to reach 6,665 pangolins and $1,540 \mathrm{~kg}$ of pangolin scales [10].

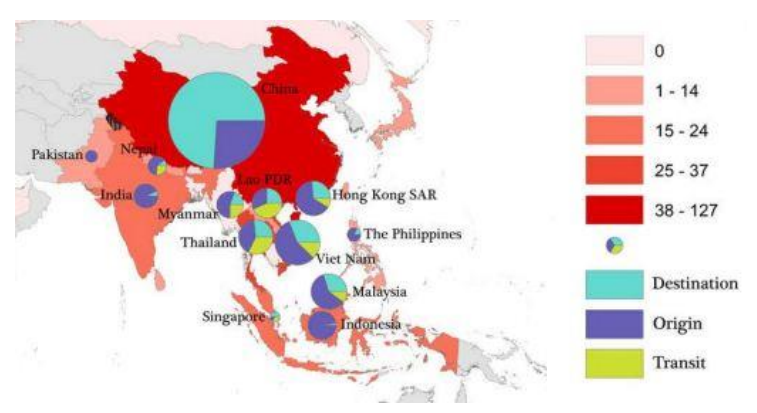

Fig. 1. Distribution Patterns of Illegal Pangolin Trade in Asia in 2010-2016 (Source: [3])

The parts of the pangolin body which become the main commodity along with the benefits of these body parts include: the scales, tongue, bile and meat. These four components are the most common parts of the pangolin body traded on the market. Pangolin scales, tongue and bile are believed to be the main raw materials of Traditional Chinese Medicine. While pangolin meat is usually consumed as a symbol of luxury that will indicate the social status of the consumer [11].

The economic value of the pangolin body parts offered in the black market is quite high. Based on Bareskrim Mabes POLRI, pangolins have an export price range of $\mathrm{Rp} 1,000,000$ to $\mathrm{Rp}$. 13,000,000 depending on the conditions, which in the form of frozen pangolin meat cost Rp. 1,000,000 to Rp. 2,000,000 per $\mathrm{kg}$ and live pangolins cost $\mathrm{Rp}$. 5,000,000 to Rp. $13,000,000$ per pangolin. Other body parts such as the tongue and bile reach Rp. 500,000 per piece [12].

Based on the problem of high demand and economic value of pangolin body parts on the international market, in the end it created an illegal activity of illegal trading of pangolin body parts. The demand for pangolin body parts also encourage the surrounding community to do illegal hunting in order to improve economic welfare [13].

The Indonesian Government itself has responded to the threat of pangolin illegal hunting and illegal trading by planning the development of the Pangolin Action Plan Conservation Strategy (STRAKT) formed by KLHK and planned to be published in 2020 [14]. The design and manufacture of the Pangolin STRAK document itself involved several parties, including the central government, the provincial government, the regional government, the private sector as well as local and international NGOs. On the part of international NGOs, KLHK's collaborative partners include: WCS-IP, WWF Indonesia, the Zoological Society of London, and Flora \& Fauna International.

While planning the preparation of STRAK documents, KLHK has currently also made a cooperation in the supervision and protection of Pangolins with other stakeholders. The program has a clear vision and mission in pangolin conservation in all conservation areas in Indonesia. The size of the working area has made the Indonesian government open partnerships with several parties to help the performance of the Pangolin STRAK program later, including the cooperation with WCS-IP. The cooperation was carried out by establishing a partnership with WCS-IP which is engaged in the conservation of flora and fauna.

\subsection{The Pattern of Cooperation between KLHK and WCS-IP in the Cooperation Framework of State-Non-State Actor}

Illegal hunting and black market of pangolin body parts pose a threat to the species that become the characteristic of Indonesia's diversity of fauna. As a country that adheres to a democratic government, the central government promotes the principle of openness which is responsible for handling problems for pangolin species. One of them is by cooperating with INGO, one of which is WCS-IP.

The collaboration between KLHK and WCS-IP was based on a Memorandum of Understanding that was signed in 2009 [15]. Based on the MOU, a number of program directions were agreed upon by both parties, including:

a) Strengthen and improve the effectiveness of management of terrestrial and marine conservation areas where WCS-IP works,

b) Strengthen policies and enforcement systems to reduce the level of trade of protected wildlife,

c) Conduct research activities or facilitate research activities that are beneficial for conservation in the Conservation Area where WCS-IP works,

d) Help increase the capacity of managers and/or the formation of a management unit in the Conservation Area where WCS-IP works.

The expected output of the entire program outlined above is the disclosure of arrests from the illegal trading of pangolins and the growth of pangolin populations in Indonesia. In fact, between 2009 and 2017, the WCS-IP in general has implemented the following programs [16]:

a) Survey of mammal populations in the Sumatera region, including pangolins

b) Suppress illegal trade of animals

c) Expand the Wildlife Crime Unit (WCU) network in Sumatera, Java, West Borneo and Sulawesi

d) Promote community involvement in monitoring activities of traded animals

e) Together with KLHK develop national and regional coordination for law enforcement in the field of wildlife crime 
f) Manage natural resources by the community (Sumatera and North Sulawesi)

g) Train local NGOs and national park staff on survey methods, data system development, identification of traded species and their parts

h) GIS, GPS and Remote Sensing Training

Based on the explanation of all the program directions outlined above, the next step is to analyze what patterns are implemented by both parties.

First, the cooperation will be analyzed using a supplementary pattern, where this pattern has the understanding that INGO can provide added value or supplementary in solving problems in the field due to limitations faced by the Government [17]. Limitations owned by the government, in this study KLHK is the human and financial resources sector. Thus, the WCS-IP through the program from 2009 to 2017 provided assistance to solve the problem of illegal pangolin trading.

Using supplementary pattern analysis, the details of the KLHK cooperation program with WCS-IP include [14]: 1) routine monitoring in the Gunung Leuser National Park and Bukit Barisan Selatan National Park. The implementation of routine monitoring is carried out through Forest Crime Unit of WCS-IP to take part in the patrol/smart patrol team. 2) Providing information and Human Resources support that is facilitated and accommodated by WCS-IP by providing the information needed for those who need the help of law enforcement personnel. 3) Assistance of pangolin illegal trade crime cases, by monitoring and assisting the arrest and trial of the perpetrators who are caught committing illegal pangolin trading. 4) Sharing information, introduction training on identification of protected wildlife species; 5) optimization of Wildlife Crime Unit (WCU) and Wildlife Rescue Unit (WRU). The whole program details are a form of cooperation that was provided by WCS-IP as the government cooperation partner by providing additional financial and personnel aspects to cover the shortcomings faced by KLHK.

Second, based on the concept of complementary patterns, in a cooperation, INGO is forced to be the front party in handling problems in various sectors and the government's tendency that by delegating authority to INGO will be more efficient through budget savings and avoiding complicated administrative processes [17]. Then in this pattern analysis will be interpreted as authority delegation programs from KLHK to WCS-IP. With this delegation, the KLHK will enlarge the oversight function in implementing cooperation.

Using complementary pattern analysis, the details of the KLHK cooperation program with WCS-IP include programs of: routine monitoring, WCS-IP in the Conservation Areas of Sumatera and Sulawesi, information support, as well as mentoring of crime cases. In routine monitoring, delegation of authority to WCS-IP is in the granting of permits and coordination support at the level of the Technical Implementation Unit in Gunung Leuser National Park and Bukit Barisan Selatan National Park. This explanation was proven by the implementation of three teams owned by WCS-IP which were the Wildlife Crime Unit, Forest Crime Unit, and
Wildlife Response Unit. Each team has their respective duties and roles. However, it is related to monitoring or field investigations carried out by the patrol team by involving FCU whose investigation results will be used during the joint patrol stage. In addition, the granting of KLHK permits to WCS-IP is by giving authority to manage FCU investigation results data by WCS-IP before being used together [14].

The process of delegating authority was also found in the information support program carried out by WCS-IP. The delegation of authority at the site level by KLHK to WCS-IP related to information support in the form of managing the results of routine monitoring that does not have to be centralized at the government. Data from the two national parks are then first managed by WCS-IP which is then reported to KLHK. The data sent is in the form of day by day periodic reports and reports every 3 months through coordination with the Ministry of Environment and Forestry [14]. Regarding the data obtained and managed by WCS-IP, until now the government trust WCS-IP about the data provided. KLHK's trust is based on the similarity of data published by WCS-IP with the data received by KLHK [18]. Thus, the assignment of duties and responsibilities to WCS-IP is not something to worry about causing a threat.

The last program is advocating crime cases, in which KLHK delegates' authority to WCU of WCS-IP to carry out activities to assist criminal cases from perpetrators arrested from Gunung Leuser National Park and Bukit Barisan Selatan National Park [14]. The process of assisting these criminal cases is carried out from the investigation stage to the court. During the investigation process to the court, WCS-IP has authority in several matters including:

a) Providing technical input to the investigator on what articles are used to ensnare the perpetrators

b) Providing information to investigators, prosecutors, judges who are used to enforce the law in court

c) Monitoring confiscated evidence after the verdict, both to be destroyed or released for the pangolins that are still alive

d) Carrying out case developments through WCU

As for the adversary pattern, the analysis of cooperation focusses more on the role of INGO which acts as a pressure on government policies as well as a bridge that connects the desires of minority communities with the government1. However, based on the data as well as interviews conducted during the study, WCS-IP did not act to suppress government policies and instead even shared a vision with the government. This was proven in a number of circumstances, which is in the way WCS-IP revised government policies and regulations, the way WCS-IP accommodated the wishes of the community, as well as the role of the donor country's participation for the KLHK.

By way of WCS-IP revising government policies and regulations, INGO which is based in the United States is quite encouraging by giving advice in changing laws without having to ask, because the government also has an agenda for revision of Government Regulations and Laws. Giving advice from WCS-IP to the government is proven in the form of revising Law Number 5 of 1990 
and revision of PP 7 of 1999. The revision was carried out through technical support, research (regulatory analysis) and facilitation of meetings. WCS-IP support took the form of the involvement of the INGO staff in the formulation team for the draft revision of Law Number 5 of 1990, plus facilitation of meetings both inviting KLHK and LIPI [14].

In addition, analyzed using KLHK's view of donor countries, KLHK both at the central and site level, do not consider sources of funds from foreign countries as a threat but rather as an opportunity. This was stated by the Staff of the Application of International Conventions, Directorate of Biodiversity Conservation, KLHK, Mrs. Niken in an interview (2019), due to the reason that donor countries are under the umbrella of international conventions which are the biodiversity conservation conventions. When the position of Indonesia is a member of an international convention, its existence is guaranteed by the membership of all countries. Another reason is the common vision and mission, so that both donor countries from foreign countries and the Ministries that manage the conservation and prevention of pangolin trade have the same interests [18].

WCS-IP also seeks not to incite the community if it does not agree with government policy. WCS-IP is in fact tries to increase community awareness and sensitivity through creative and fun ways, such as conducting campaigns with more emphasis on community participation. The presence of campaigns that were made both in person and online made the Indonesian people sensitive and concerned about the threat of pangolin illegal trading [19].

Based on data exposure and analysis of all patterns: Supplementary patterns, complementary patterns, and adversary patterns, one of the three patterns can be more dominant [20]. In the cooperation of WCS-IP and KLHK, supplementary and complementary patterns are more prominent than other patterns. The prominence of supplementary and complementary patterns is based on the analysis of shared vision and mission factors, the intensity of coordination and trust that has been analyzed from the exposure of data and adjusted for the cooperation of state-non-state actors.

In the program plan contained in the MOU, there is an element of common vision and mission set forth in the "Wildlife Management and Conservation" program plan, and is realized through routine monitoring programs, mentoring crime cases, to the optimization of WCU and WRU. The same vision and mission can also be found in the pattern of complementary cooperation with the division of authority of the work, through the same "Wildlife Management and Conservation" program plan as the supplementary pattern. The implementation of the authority granting program from KHHK to WCSIP is in accordance with the concept of complementary patterns. However, it is different from the two previous patterns, although they have the same vision in the program plan of "institutional strengthening and policy", but the implementation of the collaboration is different from the concept of the adversary pattern.

Prominent supplementary patterns can also be analyzed using the intensity of coordination factors. This is proofed by the KLHK's assessment that WCS-IP always coordinates before implementing programs carried out independently by WCS-IP such as routine monitoring programs. In addition, the intensity of coordination is also expressed in the form of reports, such as day-by-day reports, quarterly reports and annual reports. Based on the periodic reports made by WCS-IP which are then submitted to KLHK, it is a wellcoordinated form of coordination. Through intensive coordination, both parties can find out what activities will be carried out and can find out what deficiencies are faced by both parties.

Coordination is also found in the complementary and adversary patterns. In a complementary pattern, the granting of implementation authority in the field from KLHK to WCS-IP impacts on the implementation of coordination and the provision of routine reports. While in the pattern of adversary, the implementation of good coordination can be found when both parties work together to revise the laws and regulations.

The final factor is the trust factor, which is included in the trust in data management by WCS-IP and the interests of donor countries of WCS-IP. Some programs with a supplementary pattern require that WCS-IP along with all its personnel carry out data management before giving it to the government. However, due to good coordination, KLHK believes that WCS-IP is competent and open in terms of data management. Likewise, donor countries that are WCS-IP funders are not considered a threat, but are trusted by KLHK as an advantage and opportunity.

The trust factor can be found in the pattern of adversary, in which WCS-IP is believed to be the party that has made a significant contribution in the revision agenda of government regulations and legislation such as being a facilitator in the revision agenda of Law Number 5 of 1990. In addition, the trust factor is also found in complementary pattern, in which the KLHK gives great authority to WCS-IP to be the party supplying data on monitoring of the Pangolin species which is expected to become the KLHK's basic reference for making policies to support the achievement of conservation goals.

Based on the analysis of each pattern using the suitability of program implementation with the concept and the fulfilment of the same vision and mission factors, intensity of coordination and trust, thus the prominence of supplementary patterns can be seen in the following table. 
Table 1. The prominence of supplementary patterns

\begin{tabular}{|l|l|l|l|l|}
\hline \multirow{2}{*}{$\begin{array}{c}\text { Pattern of } \\
\text { Cooperation }\end{array}$} & \multirow{2}{*}{$\begin{array}{c}\text { Conformit } \\
\text { y of the } \\
\text { Implement } \\
\text { ation and } \\
\text { the } \\
\text { Concept } \\
\text { Factors }\end{array}$} & $\begin{array}{c}\text { Vision } \\
\text { and } \\
\text { Mission }\end{array}$ & $\begin{array}{c}\text { Coordin } \\
\text { ation }\end{array}$ & Trust \\
\hline $\begin{array}{l}\text { Supplementa } \\
\text { ry Pattern }\end{array}$ & Consistent & Fulfilled & Fulfilled & Fulfilled \\
\hline $\begin{array}{l}\text { Complement } \\
\text { ary Pattern }\end{array}$ & Consistent & Fulfilled & Fulfilled & Fulfilled \\
\hline $\begin{array}{l}\text { Adversary } \\
\text { Pattern }\end{array}$ & $\begin{array}{l}\text { Not } \\
\text { Consistent }\end{array}$ & Fulfilled & Fulfilled & Fulfilled \\
\hline
\end{tabular}

\section{Conclusion}

Based on the cooperation using supplementary, complementary, and adversary patterns, it can be concluded that the cooperation between KLHK and WCS-IP is more dominated by using supplementary and complementary patterns. The dominance or prominence of supplementary and complementary patterns is based on the suitability of the implementation of cooperation with the concept and fulfilment of vision, mission, coordination, and trust factors.

The similar vision and mission between KLHK and WCS-IP is implemented by providing support in the HR and financial sectors, as well as granting routine reporting authority from WCS-IP to KLHK. Provision of HR and financial support as well as routine reporting and monitoring authority is supported by good and progressive coordination factors and high trust from KLHK and WCS-IP. While adversary is less prominent due to mismatches in the implementation of cooperation with the concept that WCS-IP should act in opposition to the KLHK.

The findings in this study show that the government's relationship with INGO is an action initiated through INGO in the form of a formal legal entity in order to influence government policy and increase public awareness. As an INGO in Indonesia, WCS-IP must comply with statutory regulations that are equipped with the making of MOU so that it has a legal status. Moreover, the results of collaboration with supplementary, complementary and adversary are INGO's efforts in order to influence government policies while increasing the attention of the wider community in dealing with illegal pangolin transnational trade.

\section{References}

1. S.C.L. Chang, J.A. Eaton, K. Krishnasamy, C.R. Shepherd, V. Nijman, In the market for extinction: An inventory of Jakarta's bird markets, TRAFFIC Southeast Asia, (2015)
2. C.R. Shepherd, N. Magnus, Nowhere to hide: the trade in Sumatran Tiger, TRAFFIC Southeast Asia, Petaling Jaya, Selangor, Malaysia (2004)

3. Gomez, Lalita, et al., Scaly Nexus: Mapping Indonesia Pangolin Seizures 2010-2015, Selangor Malaysia, TRAFFIC Southeast Asia (2017)

4. WWF, Peluang dan Hambatan Pelaksanaan CITES, http://www.wwf.or.id/?4201/Pelaksanaan-CITESdi-Indonesia, accesed on 10 Mei 2019 (2010)

5. W. Kuswanda, Tingkat perburuan, pengetahuan masyarakat dan kebijakan perlindungan trenggiling (Manis javanica Desmarest, 1822) di sekitar hutan konservasi, Jurnal Politik dan Kebijakan 11(2) (2014)

6. N. Lim, Ecological research and conservation of sunda pangolin Manis javanica in Singapore, Proceeding of the Workshop on Trade and Conservation of Pangolin Native to South \& Southeast Asia (TRAFFIC), 90-93 (2008)

7. A. Rodrigues, Developing techniques to recover and analyze DNA from processed pangolin products for combating illegal wildlife trade, Simon Fraser University (2011)

8. C.R. Shepherd, Overview of pangolin trade in Southeast Asia, In: Pantel, S. and Chin, S.Y. (Eds),Proceedings of the workshop on trade and conservation of pangolins native to South and Southeast Asia, 30 Juni-2Juli 2008, Singapura Zoo, TRAFFIC Southeast Asia (2009)

9. Interview with Nofi Hardianto, Wildlife Crime Unit Officers WWF-Indonesia (2019)

10. L. Xu, J. Guan, W. Lau, Y. Xiao, An overview of pangolin trade in China, TRAFFIC Briefing Paper, TRAFFIC, Cambridge, United Kingdom (2016)

11. J. Goodman, Non-State Actors: Multinational Corporations and International Non-Governmental Organizations, Cambridge University Press (2007)

12. M. Tankandjandji, R. Sawitri, Analisis Penangkapan dan Perdagangan Trenggiling Jawa (Manis javanica Desmarest, 1822) di Indonesia, Jurnal Analisis Kebijakan 13(2), 85-101 (2016)

13. R.K. Mohapatra, S. Panda, M.V. Nair, L.N. Achharjyo, D.W.S. Challender, A note on the illegal trade and use of Pangolin body parts in India, Journal Traffic Bulletin, 33-40 (2015)

14. Interview with Sofi Mardiah, Manager of Wildlife Trade Policy, The Wildlife Conservation Society Indonesia Programme (2019)

15. Kementerian Luar Negeri Republik Indonesia, Memorandum of Understanding between The Ministry of Forestry of The Republic of Indonesia and The Wildlife Conservation Society Concerning Cooperation Program to Support Biodiversity Conservation and Conservation Area in Indonesia (2009)

16. Kementerian Lingkungan Hidup dan Kehutanan Republik Indonesia, Form Laporan Wildlife Conservation Society 2009-2017, Rencana Kerja LSM, 1-9 (2018)

17. H.K. Anheier, Nonprofit Organization: Theory, Management, Policy, Routledge (2005) 
18. Interview with Niken Wuri Handayani, Ecosystem Specialist at Directorate of Biodiversity Conservation, Ministry of Environment and Forestry of The Republic of Indonesia (2019)

19. Interview with Nining Ngudi Purnamaningtyas, Head of International Convention Implementation, Directorate of Biodiversity Conservation, Ministry of Environment and Forestry of The Republic of Indonesia (2019)

20. C.R. Shepherd, Export of live freshwater turtles and tortoises from North Sumatra and Riau, Indonesia: a case study, In: van Dijk, S and Rhodin (Eds), Asian Turtle Trade, Proceedings of a workshop on conservation and trade of freshwater turtles and tortoises in Asia (2000) 